American Journal of Neuroscience 1 (2): 34-37, 2010

ISSN 1948-9900

(C) 2010 Science Publications

\title{
The Symbolic Threshold: A Dynamic form of the Mind as an Expression of Radiant Thinking
}

\author{
${ }^{1}$ Felice Corona, ${ }^{2}$ Francesco Perrotta, ${ }^{3}$ Emilia Tartaglia Polcini and ${ }^{4}$ Carla Cozzarelli \\ ${ }^{1}$ University Telematica Pegaso-Faculty of Humanities of Naples, Italy \\ ${ }^{2}$ University of Perugia-Faculty of Science Education, Italy \\ ${ }^{3}$ Department of Education, Provincial Education Office, Youth Policy Office, Benevento \\ ${ }^{4}$ University Telematica Pegaso-Faculty of Humanities of Naples, Italy
}

\begin{abstract}
Problem statement: The definition of "symbolic species" used by Terrence W. Deacon means more complete the process of monitoring the encounter between semiotics and cognitive sciences neurosemiotics better defined. Approach: The mechanism of the symbolic threshold means that it is put in place an approach to reality no longer seen as a representative of simple association, but under a restructuring or a recombination, at least relatively stable, a number of different elements in a hierarchical plan. Possible will be a channel for research that is based on the theoretical model called "symbolic" and use the model interactive / cognitive develop through which different forms of language, communication and supports the expression and actions of each of us. From the neurobiological point of view, with regard to neuronal function, several theories are based on brain function as a binder with extreme plasticity, consistent with fragments of information to higher levels of the brain are organized and interact in order to acquire meaning. These transactions are done through organizing maps consist of groups of neurons, synapses and neurotransmitters, continuous regeneration to form categories of objects and events to recognize. Results: The most effective in building a map of the difference of a traditional information technology, borrowed from the language suggested by our mind, are much more spontaneous and direct .The study showed the effectiveness of this tool as the construction of knowledge of the inexhaustible capacity of the mind during laboratory work at the Degree of Education, University of Salerno (Italy), compared to affected users mainly adopt systems, strategies and possible interventions for teaching in kindergartens and adolescence. Conclusion: Applicability of the questionnaires were administered in teaching and scientific mind map. The consequences of the administration of the questionnaire has far exceeded expectations and led the students, the motivation to carry out projects to promote knowledge of the fundamentals of experience in various fields and disciplines, through a system that is considered usable, functional, from early childhood, particularly for people with disabilities.
\end{abstract}

Key word: People with disabilities, cognitive neurosemiotics, interactive model, cognitive maps, synapses and neurotransmitters, radiant thinking

\section{INTRODUCTION}

The definition of "symbolic species" used by is the most complete summary of the process following the encounter between semiotics and cognitive sciences neurosemiotica better defined. Deacon in this book focuses on some questions that highlight important aspects of aesthetic epistemology of knowledge. In particular, the researcher focuses on the definition of "symbolic threshold". The term "threshold" in this case refers to an idea of the mind and dynamics of the case. In that regard, Mauro Ceruti speaks of a threshold effect as of the most interesting elements of the creative processes. This effect becomes a situation in flux, in which they intersect multiple contingencies, a result obtained with well-defined relations. The mechanism of the symbolic threshold means that you put in place an approach to reality is no longer seen as a simple association representative, but under a restructuring or a recombination, at least relatively stable, a number of different elements in a hierarchical plan. Deacon as Morin, expressed in terms of co-evolution and progress of the relationship between biological growth of the human brain process cerebralization, and cognitive development, technology and human language. He introduces the concept of the spacers from man's own

Correspondig Author: Felice Corona, University Telematica Pegaso-Faculty of Humanities of Naples, Italy 
language communication is rather typical of all life forms. The language becomes exclusive to humans because, unique, and it came built into it by developing a mind able to symbolically represent their experience. This symbol is referred diverges from that of computational cognitivism according to which the mind represents the world through symbols and their manipulation. Instead, a dynamic symbol, inspired by the epistemology of Charles (2003), shares Deacon the constructive aspect of the process of symbolization: "The symbolize directly into the construction of cognitive objects, leading the way in which events are organized and what they mean”. Neisser (1987) express these four parameters related to the theory of multiple self-identified five types of self-knowledge: "the ecological self, which has a perception of self in relation to the physical and the interpersonal self, perceives himself involved in an interaction, the extended self that extends into the past and the future, the private self that is part of the self is not accessible and not shared with others, the self concept that expresses the beliefs and theories about ourselves". And this is what we are interested in, the applicability of an experiment aimed to demonstrate the effectiveness of an educational approach focusing on self-knowledge through signs, symbols, images and keywords that characterize the radiant thinking, the thinking Radiant, and that is reflected in the structure of Mind Maps (Buzan and Buzan, 2003).

Objectives and functions: It can be a channel of research that is based on a theoretical model called the "symbolic" and makes use of the interactive model/cognitive approach through which they develop various forms of language, communication and claims the expression and gestures of each of us. It is important to understand how to evolve in identifying symbolic functions. In fact, the construction of experience which belongs to every human being requires a continuous exchange world-I, object, worldencompassing relationship with the space of gestures, space objects and space of others (Goffmann, 2009) compared to speak of these dynamics and symbolic interactionism maintains that the sign is the first input channel for the individual from the early stages of development. Consequently, the claim that the patterns do not exist in reality but in the mind and imagination while the concepts that belong to the categories of proceedings and the intellect (Markus, 1977). Speaks of self-schemas, and knowledge structures that result in memory all the representations that the person has their own attributes, roles, past experiences, future projections. Each of the functions of the ego-mind convert sensory-motor patterns in thought patterns. The birth of thought, a "self-mind", is thus the product of an effort that our brain is to keep under control the tension placed on it following the emergence of multiple stresses (Corona, 2008).

The primary purpose was to bring out through this method of forms of knowledge which is not the world of objects but that include the production of any person involved with others and his emotional life. We have aimed not so much on verbal communication but on the non-verbal part of a form of language of gestures, symbols, and that is a very powerful form of communication. showed that language is the best example of all the symbol systems is a mature adult is the stage during the development of the child when he took over a first mechanism to symbolize the final and most important phase which is between five and seven years and is kind of notation as in this stage the child uses a system or scheme that will help them remember. Therefore, learning always occurs in a particular context, and also implies specific ways of organizing information. But we believe learning is not just transfer the memory thanks to an association of reinforcement. The goal is to figure out what is relevant, and then imagine how important variables are associated. It means to select and organize, and sometimes re-encode what we have already learned. The medium is represented by Radiant thinking that we as a project to "educate to understand" where these qualities are enhanced by combining procedures to grasp its deeper meaning. The success and the achievement of an objective is closely related to the method used.

\section{MATERIALS AND METHODS}

From the neurobiological point of view, with regard to neuronal function, several theories have been based on brain function as a collector with extreme plasticity, consistent with fragments of information to higher brain levels are organized and interact in order to acquire meaning. These transactions are done through organizational maps consist of groups of neurons, synapses and neurotransmitters, continuous regeneration to form categories of objects and events to recognize. So the mind is represented as a structure composed of memories, affections, designs, patterns with the task of safeguarding the identity and integrity of the individual at all times and therefore subject to adjustments and remodeling during all stages of its evolution. These aspects are represented and easily transferable into a Mind Mapping. In practice, we decided to highlight the mental images, the way we form images of objects, people and situations. The images combined with words as an expression of 
radiant thinking activate multimodal information on various sensory modalities, acoustic, tactile and visual. The methodological consequent is discovered through according to which the brain has led to self-sustaining and therefore the memory capacity is limited, but the more you exercise more it expands. In fact, the formulation of Mind Map understood as a manifestation of the "radiant thinking" is due to Tony Buzan who worked on the development of this theory from 1970 until 1982. The Mind Map has four essential characteristics: (1) the subject of attention is focused in a central image, (2) the nuclei of the most important thought of themselves as radiating branches that stem from the central, (3) provide for the branches keyword and the less important themes are always represented in the form of branches that start at center branches, (4) the branches forming a nodal structure. One of the decisive stages, before coming to the realization of this research was to collect An Encyclopedia of the Brain and use it, the notes and the continuous updating of this collection have led to a definitive and concrete conception of the concepts of Radiant Thinking, the 'thought activity that is realized through countless groups on the basis of information derived from external stimuli combined with existing data and Mind Mapping, one of many possible applications of creative thinking. This method originated in England has been released and taken up by many experts, most of the world, following the collaboration that occurred with (Gelb, 1988; North, 2001) and the rise of T. Buzan Centre, founded by the scholar with. This brief review serves to deepen the endless brain function from a dynamic point of view of the case and to the knowledge of the methodology we applied Radiant Thinking.

\section{RESULTS AND DISCUSSION}

The most effective in building a map is that unlike a traditional information technology, borrowed from the language suggested by our mind, are much more spontaneous and direct. The advantage is that you can synthesize a large number of pages in just a few sheets. Furthermore, using all our abilities not only as logical and rational so that we can construct maps to "burst explosion", leaving the thoughts to flow free. The fields of application of the map are many, ranging from the study, the notes, the decision-making sphere, participation in conferences or seminars, the implementation of projects for a variety of professions and in various areas of intervention, up to brainstorming. All this as part of an educational strategy that will help develop skills and be introduced to the teaching units as a method of intervention implemented to monitor the processes of teaching/learning. The trial has highlighted the effectiveness of this instrument as the construction of knowledge of the inexhaustible capacity of the mind during the workshop activities held at the Degree of Education, University of Salerno (Italy), compared to users primarily interested in acquire systems, strategies and possible interventions for teaching in kindergarten and adolescence. Applicability of the questionnaires were administered in teaching and scientific mind map. The fallout from the administration of the questionnaire has far exceeded expectations and resulted in students, motivation to implement projects aimed at promoting knowledge of the fundamentals of experience in various fields and disciplines through a system already considered usable and functional from early childhood, particularly for people with disabilities. You have exceeded the narrow view of the use of M. M., initially detected by the balanced view, at the conclusion of the workshop location, Maps, and inter-group work, well structured and diversified than a linear view of strategy and single-issue "rigid" and should not be stereotyped to give emphasize those that are our abilities different.

\section{CONCLUSION}

The effectiveness of a practice may undermine stereotypical. In fact, it often commits the mistake of dwelling too much on information from different areas of knowledge and asks the individual to a forfeiture order processed data and forms "predetermined". The reliability of the system is capable of starting only from the resources of each individual as each supports the arguments with different styles and skills, so that both teaching and learning are more effective and meaningful.

\section{REFERENCES}

Buzan, T. and B. Buzan, 2003. Mappe Mentali. How to use the most powerful tool for access to the extraordinary ability of the brain to think, create, study, organize. 1st Edn., Alessio Roberti Editore, Italy, ISBN-10: 8888612025, pp: 351.

Corona, F., 2008. Gli apprendimenti della mente. Lavorare sulle diverse abilità. 1st Edn., Pensa Editore, Lecce, ISBN: 9788861520448, pp: 156.

Gelb, M.J., 1988. Present Yourself!. 5th Edn., Jalmar Press, USA., ISBN-10: 0915190516, pp: 108.

Goffmann, E., 2009. L'interazione Strategica. 1st Edn., II Mulino, Bologna, ISBN-10: 8815128069, pp: 176.

Markus, H., 1977. Self-schemata and processing information about the self. J. Personal. Soc. Psychol., 35: 63-78. DOI: 10.1037/00223514.35.2.63 
Neisser, U., 1987. Concepts and Conceptual Development: Ecological and Intellectual Factors in Categorization. 1st Edn., Cambridge University Press, USA., ISBN-10: 0521322197, pp: 317.
North, 2001. Get ahead. 5th Edn., BC Books, British Columbia, ISBN: 9781874374008, pp: 96. 